\title{
Using Multiple High-Impact Practices to Improve Student Learning in an Undergraduate Health Science Program
}

\begin{abstract}
Chandrakala Ganesh1 and Jason A. Smith2
Abstract: Problem-based learning can be an effective educational approach for students entering the health care field. While broadly used in graduate and professional education in the health sciences, it is less widely used in undergraduate programs. We discuss the use of problem-based learning as part of an approach to address failure rates in select Health Sciences courses and poor critical thinking skills. While our results were mixed, we saw an overall improvement in student outcomes. Problem-based learning experiences prepare students better for demands of the real world.
\end{abstract}

Key Words: problem-based learning, case-based learning, high impact practices, student learning outcomes, health sciences

The Health Sciences program is one of the largest at California State University, East Bay (CSUEB). The program has grown by 68 percent from 838 students in 2011 to 1,411 students in 2016 (Institutional Research, Analysis, and Decision Support [IRADS], 2016). The Health Sciences program is also one of the smaller programs with respect to full-time faculty, with 8 fulltime tenure-track faculty in 2016. The shortage of faculty and growth of students is an example of the pressures and challenges facing the California State University (CSU) system. In this article, we describe our experience in transforming the health sciences curriculum, by specifically focusing on courses with high failure rates and those that serve as bottlenecks for student graduation. Bottlenecks in graduation occur when students are unable to either enroll in required courses and/or are unable to graduate because they did not complete the required courses successfully. A recent CSU survey found that there were many reasons for bottleneck these problem courses, such as: deficiencies in funding, space, and qualified faculty; students repeating classes; and other factors (Kiss, 2014). In this case study we examine one cause: failure rates in select courses that are critical for graduation. We also demonstrate the improvement in student outcomes and student success as a result of curriculum redesign.

Curriculum transformation is challenging when the change will impact a large group of students with only few full-time faculty available to manage the ripple effects. We were able to embark on this transformation, in part, due to a generous grant awarded in 2014 by the Chancellor's Office at California State University. The Promising Practices grant from the Chancellor's office which provided an opportunity for us to redesign select courses to improve student success and learning. Specifically, we focused on a sequence of interdependent courses with high failure rates.

In CSUEB's Health Sciences program, students are required to take three related courses: Health Care Systems (henceforth referred to as Health Systems), Health Legislation and

\footnotetext{
1 Department of Nursing and Health Sciences, California State University, East Bay, 25800 Carlos Bee Boulevard, Hayward, CA 94542, chandrakala.ganesh@ csueasbay.edu

2 Department of Nursing and Health Sciences, California State University, East Bay, 25800 Carlos Bee Boulevard, Hayward, CA 94542, jason.smith@ csueastbay.edu
} 
Government Programs (henceforth referred to as Health Policy) and Health Care Law and Ethics (henceforth referred to as Health Law). The Health Systems course provides an overview of the systems and organization of health care in the US; the Health Policy course explores current state and federal legislation and the historical developments of health programs; the Health Law course provides an overview of legal and ethical issues encountered by health care practitioners. Students take the courses in the order listed above, with the latter classes having the earlier courses as prerequisites. Since CSUEB is on the quarter system, students generally complete the series within one year. Failing even one of these classes can jeopardize a student's timely graduation.

\section{Evidence of the Problem}

We used institutional data on student grades from 16 consecutive quarters: Fall 2012-Summer 2016 for our analysis (IRADS, 2016). We piloted the redesign and transformation in Summer 2015 and implemented it in Fall 2015. We refer to the data from Fall 2012 to Spring 2015 quarters as "pre-redesign", and refer to data from Summer-2015 to Summer 2016 quarters as "post-redesign". Pre-redesign, there were 18 sections of the Health Systems course, 19 sections of Health Policy course and 15 sections of the Health law course. In all, 3031 students enrolled in the 3 courses combined prior to redesign. We have completed 12 sections of the Health Systems course, 13 sections of the Health Policy course, and 11 sections of the Health Law class post-redesign. In all, 1454 students enrolled in the redesigned course sections.

There were two issues that confronted us in the failure rates for these courses. First, the high percentage of students who did not pass the courses. Second, a high variability among the grade distributions among various sections of courses. Closer examination of data also showed that, prior to the transformation, failure rates for these courses varied unpredictably between zero percent and 37 percent depending on the instructor teaching the courses. As shown in Table 1, over the three-year period (Fall 2012-Spring 2015), an average 11 percent of the students repeated the Health Systems course, 13 percent repeated the Health Policy course and 9 percent repeated the Health Law course. Taken together over three years, on average, 11 percent of our enrolled Health Sciences students were repeating one of the 3 courses.

\section{Table 1. Grade distribution of students prior to redesign (Fall 2012-Spring 2015)}

\section{Health Systems Health Policy Health Law ALL 3 combined}

$\begin{array}{lcccc}\mathrm{N} & 1090 & 1111 & 830 & 3031 \\ \% \text { Passing Grade (A-C) } & 86 \% & 86 \% & 88 \% & 87 \% \\ \% \text { Failures (C- and below) } & 10 \% & 11 \% & 8 \% & 10 \% \\ \% \text { Others (Withdrawal, } & & & 4 \% & 4 \% \\ \begin{array}{l}\text { Withdrawal- } \\ \text { Unauthorized) }\end{array} & 3 \% & 4 \% & & \end{array}$

After a review of syllabi from the courses, we found that most of the courses used a traditional lecture-based model. In class, the primary focus is on the instructor and the lecture content, while student engagement is restricted to discussions based on material presented in class. In this approach, assessment of learning outcomes is primarily through quizzes and exams, and Journal of the Scholarship of Teaching and Learning, Vol. 17, No. 2, April 2017. josotl.indiana.edu 
occasionally through group presentations and point papers. We believe that this approach is valuable for short-term retention of content. Previous work has shown limited gains in critical thinking through lectures and quizzes (Stanger-Hall, 2012; Tiwari, Lai, So \& Yuen, 2006).

At CSUEB, critical thinking is both a program learning outcome and an institutional learning outcome. All students in the Health Sciences program are required to complete a 90-hour supervised training internship/volunteer position in a health care or social service organization. In addition to completing their 90 hours successfully, they write an internship report that integrates their field experiences with their health sciences coursework. When we examined the failure rate in our capstone course, we found that, from 2012 to 2015 , approximately 8 percent of students enrolled in the class did not pass the internship report component. We were concerned that graduating students were struggling to integrate theory with practice and would be entering the health care field with a superficial knowledge of health care topics, rather than a deeper application of learned concepts.

\section{Our Goals}

There were three problems we wanted to address: (1) failure rates in the select Health Sciences courses (2) poor critical thinking skills and (3) bottlenecks in enrollment. We addressed these problems using specific tools in pedagogy and curriculum management. First, to reduce failure rates we replaced quizzes, midterm and final exams with team work projects as well as a wide range of writing assignments. Next, to develop critical thinking skills we implemented problembased learning instruction as a pathway to understand and solve complex problems in health care. Finally, we reduced bottlenecks in enrollment by enforcing prerequisites and tweaking course offerings to fit with the curriculum road map. While all three measures are equally important, we do not discuss bottleneck issues and enrollment management in this article, as they are more administrative in nature and would necessitate a larger discussion of enrollment management and policy and their effect on pedagogy. In this project we focused on implementing pedagogical changes in the redesigned courses. We believe that implementing problem-based learning in these courses would not only help to mitigate some of the existing the problems, but also create a future generation of critical thinkers in health sciences.

\section{Problem Based Learning: Linking theory to viable solutions}

Problem-based learning (PBL) has its origin in health care and is a particularly effective method for teaching medical students and students entering the health care industry. PBL is studentcentered and provides relevant learning opportunities that incorporate real-world challenges common in the discipline of instruction. This approach introduces students to the content through the process of problem-solving, instead of first learning the content and then applying it to the problem. Emphasis is on critical-thinking as well as multidisciplinary learning. Health care is fraught with complex scenarios and problems that do not have one "right" answer. Such complex problems don't have a defined trajectory and solutions to these problems are not true-or-false but good-or-bad. Often the solutions themselves have unintended consequences which lead to additional problems (Rittel \& Weber, 1973).

PBL is the mainstay in many graduate schools including specialized programs such as medicine and nursing (Agbeh, 2014; Hoffman, Hosokawa, Blake Jr, Headrick, \& Johnson, 2006; L'Ecuyer, Pole, \& Leander, 2015). Problem-solving abilities and critical thinking are much needed 
skills in the workforce as well (Flores, Matkin, Burbach, Quinn, \& Harding, 2012). One could say that undergraduate schools are committing a disservice to their students by not preparing them for this transition. This makes a strong case that undergraduate students would benefit from early introduction to PBL, irrespective of their future career trajectory: graduate school or employment.

The PBL approach presents a real-world problem built into the content of the lecture, thereby challenging the students to work through and come up with as many solutions as possible, by using their experiences. This is in contrast to traditional lecture-based learning, where the lesson is introduced in advance of the problem (Agbeh, 2014). When students are only lectured to, they fail to make sense of the content and are unable to find ways to apply the newly learned content to real-life scenarios. PBL can reach far beyond simply teaching future clinicians; it has also proven to help clinicians with patient interactions and other multidisciplinary demands of health care work as well (Bate, Hommes, Duvivier, \& Taylor, 2014). Coaxing students to develop ideas and come up with solutions to a problem they may know little of, helps them become "flexible" thinkers (Dolmans, De Grave, Wolfhagen \& Van Der Vleuten, 2005). This becomes a resource from which they can draw from, once they enter their chosen clinical fields. The inverted manner in which PBL presents the expected learning content, challenges students to escape their comfort zone in order to make advances in their learning capacity, based on their personal and professional interests (Alessio, 2004).

One of the tenets of the PBL process is cognitive engagement and reflection, where students reflect on their previous experiences after reading through a specific problem. This reflection helps the students come up with questions they may need answered before moving forward (Hemlo-Silver, 2004). The transition from traditional learning to PBL is smoother and entices positive reactions from students when they are given ample opportunities to practice and develop their critical thinking abilities (Alessio, 2004).

Group work is a mainstay of PBL and helps with the reflection process because some undergraduate students may lack life experiences or may not have discipline-specific professional experience. PBL also helps students develop a sense of community, and, as they progress through the curriculum in a group, they become comfortable with one another making it easier for them to express many out-of-the-box suggestions without fear of being rejected (Agbeh, 2014; Bate et al. 2014). Ultimately both the individual and the group benefits from their shared experiences, further reinforcing their future as lifelong learners.

\section{Course redesign using Fink's backward design framework}

We redesigned the select Health Sciences courses primarily using Dee Fink's model for creating significant learning experiences using backward design (Fink, 2013). First, we identified the results desired in the Student Learning Outcomes. Next we incorporated the activities that would help us in measuring these outcomes (Assignments). Finally, we incorporated acceptable levels of evidence that would support that student learning has occurred (Assessment). Since students take the three Health Sciences courses one after another (with earlier courses as prerequisites for the subsequent ones), we redesigned the courses such that skills will be Introduced in the first course, Developed/Practiced in the second course and Mastered in the third course in the series. As shown in Table 2 and Table 3, the three main skills we focused on were: Critical Thinking skills, Research and Writing skills, and Teamwork Skills. 
Ganesh and Smith

Table 2. Progression of Skills in the 3 Health Science Courses

\begin{tabular}{|c|c|c|c|}
\hline Course & Health Systems & Health Policy & Health Law \\
\hline \multicolumn{4}{|c|}{ Progression of Skills } \\
\hline & Introduce & Develop & Master \\
\hline Health Care & Identify Common & Analyze and Solve & Analyze and Solve \\
\hline \multirow{2}{*}{ Content } & and/or Well-Defined & Common and/or Well- & Uncommon and/or Ill \\
\hline & $\begin{array}{l}\text { Problems in the Health } \\
\text { Care Context }\end{array}$ & $\begin{array}{l}\text { Defined Problems in } \\
\text { the Health Care } \\
\text { Context }\end{array}$ & $\begin{array}{l}\text { Defined Problems in } \\
\text { the Health Care } \\
\text { Context }\end{array}$ \\
\hline Research \& & Learn and Practice & Conduct Basic Legal & Independently \\
\hline Writing & Basic Research Skills & and Policy Research & $\begin{array}{l}\text { Conduct Legal and } \\
\text { Policy Research }\end{array}$ \\
\hline Teamwork & $\begin{array}{l}\text { Work Effectively in } \\
\text { Teams }\end{array}$ & $\begin{array}{l}\text { Work Collaboratively } \\
\text { in Teams }\end{array}$ & $\begin{array}{l}\text { Work Seamlessly in } \\
\text { Teams }\end{array}$ \\
\hline
\end{tabular}

Our goal was to ensure that when students in the Health Sciences program complete the third course in the 3-part series (i.e. Health Law), they should be able to analyze and propose solutions to uncommon and complex health care problems presented to them. These problems are often ill-defined with many causative factors and generally, solutions to these problems have unintended consequences. Analyzing these ill-defined problems requires higher-order critical thinking and problem-solving skills. Working backwards, we designed the Health Policy course such that students were able to hone their critical thinking skills by developing experience in analyzing and solving well-defined problems in health care.

Similarly, in the Health Care systems course, the first in the series, students were expected to be able to identify common problems in health care. When we implemented problem-based learning in these courses, we realized that students, especially those in the introductory Health Systems course were unprepared and did not have a good learning experience. As this was their first exposure to problem-based learning techniques, they were constantly anxious about the openended format of the course. While PBL alone can be effective, it can be challenging for both students and faculty who have predominantly experienced the didactic method of instruction. So, we decided to use a case-based approach first and then transition students to PBL. There are two important reasons for doing this. First, case-based learning helps to break down complex material into manageable parts. Second, it fosters critical thinking and pushes students towards the path of problem-solving (our overarching goal). Hence, in the Health Care systems and Health Policy course we used case-based teaching to discuss complex real-world scenarios in class, so students can develop analytical and critical thinking skills. We introduced PBL strategies in the Health Care Law course.

We also expected that by the end of the third course (Health Law), students should be able to work seamlessly in teams and also independently conduct basic research required to complete their writing deliverable. Using this as a benchmark, we designed the courses such that there is greater instructor involvement and handholding in the introductory course, with greater student independence in the final course. For example, in the Health Care Systems course, for the main writing component (Literature Review), we scaffolded the deliverables such that students receive feedback on their research strategy, outline, annotated bibliography and their literature review draft Journal of the Scholarship of Teaching and Learning, Vol. 17, No. 2, April 2017. josotl.indiana.edu 
before the final submission is due. Instructors also "check-in" weekly or bi-weekly with teams in class to ensure effective team communication. In the Health Policy course, for the main writing component (Policy Memo), students are encouraged to use scaffolding techniques for completing the policy memo, and instructor feedback is provided only for the full draft. The onus is also on team members to meet regularly and to resolve conflicts with limited instructor involvement. We believe that this method better prepares students to complete both the team project and research paper in Health Law course, the final course in the series.

\section{Table 3. Student Activities in the 3 Health Science Courses}

\begin{tabular}{|c|c|c|c|}
\hline Course & Health Systems & Health Policy & Health Law \\
\hline \multicolumn{2}{|c|}{ Case based learning } & Case-based learning & BL \\
\hline $\begin{array}{l}\text { Content Delivery } \\
\& \text { Assimilation }\end{array}$ & $\begin{array}{l}\text { Lecture, reflective } \\
\text { journals, project-based } \\
\text { learning }\end{array}$ & $\begin{array}{l}\text { Group discussions, } \\
\text { Reflective journals, } \\
\text { case-based learning }\end{array}$ & $\begin{array}{l}\text { Problem-based } \\
\text { learning }\end{array}$ \\
\hline $\begin{array}{l}\text { Research \& } \\
\text { Writing }\end{array}$ & Literature Review & Policy Memo & Research Paper \\
\hline Teamwork & 2 presentations & 2 presentations & Panel discussion \\
\hline
\end{tabular}

\section{An Example: PBL in the Health Law class}

In the last class of the series, Health Law, we started with Fink's initial phase and determined the situational factors for the course; the learning goals, the appropriate learning and teaching activities; to properly situate the course in the field, and to determine the activities and structure for the course. We outlined the situational factors that were important, including the state of the field, employer expectations, and student and teacher characteristics (Fink, 2013). In discussions with employers and a review of the field, we determined which problem-solving skills and team work skills were particularly important. In some cases, team work skills were more important than subject-matter knowledge. With this information, we were able to work backwards in the sequence of courses to ensure that students had opportunities to practice and master these skills.

In the Health Law class, each student worked on a research topic and spent the quarter answering the problem given within the context of health law and ethics. In class, the instructor answered questions posed by students and walked students through other cases to demonstrate and reinforce the approach to problem-solving. One research project example was the following, "Laura is 16 years old. She comes to your office to have her wisdom teeth removed. This procedure requires anesthesia. Laura's mother completes the intake forms and informed consent documents for Laura. She marks "Not pregnant" on the form. Once Laura is in the chair and you are preparing to administer the anesthesia, she says to you "I think I am pregnant." What are the legal and ethical implications here? What do you do?" The student given this problem identified the key issues to formulate a response. What are the medical implications for performing oral surgery on a pregnant patient? To whom does the physician owe a duty? Who can consent? What are the state laws around medical decision-making for minors? What are the state laws for reproductive decision-making? As the student worked to develop an answer to this question, the instructor reviewed different laws and ethical theories in health care and explored their application. The student also concomitantly worked with the team in the application of issues to problems. See Table 3 to compare assignments and approaches. 


\section{Specification Grading for Assessment}

We made a significant change in our approach to grading in the 3 classes by replacing the traditional system of points-based grading with specification grading. Specification grading is an approach to assessment that emphasizes students "getting it right" rather than points and grades themselves. The goal of specification grading is to successfully meet the objectives of a course and it grades course performance based on a student's ability to complete these objectives (Nilson \& Stanny, 2015). In this approach the instructor does not award points for how well or poorly an assignment is completed. Instead, the focus is on whether students complete a set of specifications. These specifications detail to students what they must accomplish to earn an A, B, C or D in the course. Only when a student meets all the specifications does the student get credit for the assignment. The student gets multiple attempts to complete the assignment, meet the specifications and improve the deliverable in each step.

In setting the specifications for the Health Sciences courses, we ensured that the specifications for the lowest passing grade (i.e. C) demonstrated that students have learned the fundamentals of the course. Nilson and Stanny (2015) mention that this is especially critical, when a course is part of a sequence of courses, where, it is important to demonstrate understanding of a set of baseline skills successfully before moving to the next course. Likewise, students earning an $\mathrm{A}$ in the course have demonstrated competency in course objectives.

\section{Results}

Since grades are a widely accepted measure of the student's academic performance, we chose to use grades as the metric to evaluate the initial success of our redesign. Since we used specification grading, we also had greater confidence in the use of grades as a measure of assessment. While there are still issues with the use of grades for assessment, in this case, we believe that the use was appropriate. Here we present quantitative and descriptive data on student grades. As mentioned earlier, the data presented here was obtained from CSUEB's Institutional Data Center. Student grades for each of the 3 courses: Health Systems, Health Policy and Health Law were compiled for each quarter, Fall-2012 though Summer-2016. The course redesign and transformation were piloted in Summer-2015 and fully implemented from Fall-2015 onward.

Table 4. Grade distribution of students, post-redesign (Summer 2015- Summer 2016)

$$
\text { Health Systems } \quad \text { Health Policy Health Law All } 3 \text { courses combined) }
$$

$\begin{array}{lcccc}\mathrm{N} & 519 & 528 & 408 & 1454 \\ \% \text { Passing Grade (A-C) } & 86 \% & 90 \% & 87 \% & 87 \% \\ \% \text { Failures } & 6 \% & 7 \% & 9 \% & 7 \% \\ \begin{array}{l}\text { (C- and below) } \\ \% \text { Other } \\ \text { (Withdrawal/Withdrawal }\end{array} & 8 \% & 3 \% & 4 \% & 5 \% \\ \text { Unauthorized) } & & & & \end{array}$

Journal of the Scholarship of Teaching and Learning, Vol. 17, No. 2, April 2017. josotl.indiana.edu 
As seen in Table 4, the percentage of students failing any of the 3 classes under consideration dropped from 11 percent to 7 percent. When examined separately, we find that for the introductory Health Systems course, the percent of students failing course decreased by 4 percentage points. Similarly, in the next course in the series, Health Policy, failure rates decreased 4 percent post-redesign. These numbers are encouraging and suggest that students are receptive to the course redesign, which further correlate with better student learning outcomes. In contrast, for the course Health Law, the failure rates have increased by 1 percent in comparison to the failure rates prior to course redesign. Closer examination revealed that the higher failure rate was due to one section of the class. While the overall percent of withdrawals from the 3 courses combined has seen a slight increase, Health Systems course in particular has shown a large increase in the percent of withdrawals from 3 percent pre-redesign to 8 percent post-redesign. We believe that this is primarily due to the timing when students take this course in the curriculum. The Health Systems class is one of the first classes in the Health Science curriculum to introduce health care content through case-based learning and requires that students complete a writing assignment and work in teams. It is likely that students find it difficult to adjust to the new framework of this classes, or it is indicative of challenges faced by students are they juggle work, family, and other personal problems along with course work. Nevertheless, our approach in modifying the select classes using an overarching PBL framework, through varied written assignments and team work helped in decreasing failure rates and bottlenecks in enrollment one year post-redesign.

\section{Limitations}

There are several limitations to this study. One of the foremost is that it uses student grades to determine success/failure in a course. A better way to capture success or failure in a course would be to measure the critical thinking of students via qualitative methods or by a combination of grade distribution and qualitative methods. This study also relies on descriptive measures rather than statistical significance of the data presented. We have also not stratified student data by demographics to determine associations with failure rates. It is likely that students' grades were influenced by challenges that students face outside the classroom settings.

\section{Implications}

The results have implications for our program and for students. First, we were previously unaware of the level of variability of grade distributions in course sections. We considered this grade variability unfair and following this study, have received another grant to standardize syllabi across sections and are investigating grade variability in other program courses. This variability suggests the need for additional and on-going training and collaboration among the faculty; particularly lecturers and other part-time faculty. Second, this approach to the classes is resource-intensive. Course caps were reduced and significant resources were expended to train part-time faculty and lecturers in this approach. Many contingent faculty found the training and implementation demands for the course daunting. Finally, while the changes were effective overall and resulted in improved student outcomes, a modified PBL approach may be difficult to implement and maintain in such a few number of courses. Overall, the experience has influenced our approach to the upcoming transition to a semester schedule as our entire program is being transformed to a casebased and problem-based approach.

Journal of the Scholarship of Teaching and Learning, Vol. 17, No. 2, April 2017. josotl.indiana.edu 


\section{Conclusion}

PBL prepares students for their future careers by introducing them to problem-solving skills. Instructors though must expend time and effort to ensure that their undergraduate students are, at the very least, gradually introduced to this method of learning. Being suddenly faced with PBL has been proven to cause apprehension, unnecessary anxieties and ultimately, failure. Different researchers have found that the level of self-confidence, social-skills, students' individual buy-in, an inviting group atmosphere, advanced study skills, social class and first-generation university students, all affect the success of students achieving flexible, critical thinking skills (ChesserSmyth \& Long, 2012; Dolmans et al., 2005; Hemlo-Silver, 2004; Jury et al., 2014). Our approach relies on a three-part series of courses that slowly move students from more passive learning to more active learning styles that transition into more individual problem-solving. This approach allows student to slowly improve and to build the confidence to solve problems on their own in a supportive setting.

Students should leave their campuses with more than just a diploma. Exposing them to PBL experiences prepares them for the demands of the real world and will help them to succeed in their future fields. The health care field is evolving and the subject matter that students learn rapidly becomes outdated. For example, the health care system in the United States has radically changed with the passage of the Patient Protection and Affordable Care Act. ("ACA"). The ACA rendered the subject matter in many of our courses outdated almost "overnight". Graduates from our program in 2006 working in health care are now faced with health and policy issues unimagined in 2006. For example, the growing debate about outcome-based reimbursement is now a critical policy issue that we would not have imagined ten years ago and hence would not have covered it in classes at that time. When student learning is focused only on subject-matter content, they would not have the opportunity to prepare for a highly-changing field. By shifting the focus to problem-solving, critical thinking, and team work, we give our students the skills to learn on their own and the confidence to face currently undefined challenges in the health care system.

\section{Acknowledgements}

This study was possible in part due to the "Promising Practices in Course Redesign with Technology" grant awarded by The Office of the Chancellor, California State University. The authors thank Mr. Matthew Moore for his enthusiastic collaboration in the course redesign efforts. The authors would also like to thank Mrs. Roxy Flores Neale for assisting with the literature review.

\section{References}

Agbeh, A. (2014). The impact of problem-based learning on problem solving skills and a sense of community in the class room. Review of Higher Education and Self Learning, 6(24), 99-105.

Alessio, H. (2004). Student perceptions about and performance in problem-based learning. Journal of Scholarship of Teaching and Learning, 4(1), 23-34.

Bate, E., Hommes, J., Duvivier, R., \& Taylor, D. C. (2014). Problem-based learning

Journal of the Scholarship of Teaching and Learning, Vol. 17, No. 2, April 2017. josotl.indiana.edu 
(PBL): Getting the most our of your students-their roles and responsibilities: AMEE guide No. 84. Medical Teacher, 36, 1-12. doi:10.3109/0142159X.2014.848269

California State University East Bay. (2015, September 15). Cal State East Bay wins 2015 HEED award for excellence in diversity. Retrieved from http://www20.csueastbay.edu/news/2015/09/09152015a.html

Chesser-Smyth, P. A., \& Long, T. (2012). Understanding the influences on self-confidence among first year undergraduate nursing students in Ireland. Journal of Advanced Nursing, 69(1), 145-157. doi:10.1111/j.1365-2648.2012.06001.x

Dolmans, D. H., De Grave, W., Wolfhagen, I. H., \& Van Der Vleuten, C. P. (2005). Problembased learning: Future challenges for educational practice and research. Medical Education, 39(7), 732-741. doi:10.1111/J.1365-2929.2005.02205.x

Fink, L. D. (2013). Creating significant learning experiences: An integrated approach to designing college courses. John Wiley \& Sons.

Flores, K. L., Matkin, G. S., Burbach, M. E., Quinn, C. E., \& Harding, H. (2012). Deficient critical thinking skills among college graduates: Implications for leadership. Educational Philosophy and Theory, 44(2), 212-230.

Hoffman, K., Hosokawa, M., Blake Jr, R., Headrick, L., \& Johnson, G. (2006). Problem-based learning outcomes: ten years of experience at the University of Missouri-Columbia School of Medicine. Academic Medicine, 81(7), 617-625.

Hmelo-Silver, C. E. (2004). Problem-based learning: What and how do students learn? Educational Psychology Review, 16(3), 235-266. doi: 10.1023/B:EDPR.0000034022.16470.f3

Institutional Research, Analysis, and Decision Support. (2016). Data on Health Sciences students. Available from the Office of Institutional Research, Analysis and Decision Support, California State University, East Bay.

Jury, M., Smeding, A., Court, M., \& Darnon, C. (2014). When first-generation students succeed at university: On the link between social class, academic performance, and performanceavoidance goals. Contemporary Educational Psychology, 41, 25-36.

doi:10.1016/j.cedpsych.2014.11.001

L'Ecuyer, K. M., Pole, D., \& Leander, S. A. (2015). The use of PBL in an interprofessional education course for health care professional students. Interdisciplinary Journal of ProblemBased Learning, 9(1), 6. doi:10.7771/1541-5015.1497

Kiss, M. (2014). The California State University bottleneck courses survey report. Journal of Collective Bargaining in the Academy, (9), 2. 
Nilson, L. B., \& Stanny, C. J. (2015). Specifications Grading: Restoring Rigor, Motivating Students, and Saving Faculty Time. Stylus Publishing, LLC

Rittel, H. W., \& Webber, M. M. (1973). Dilemmas in a general theory of planning. Policy Sciences, 4(2), 155-169. doi: 10.1007/BF01405730

Stanger-Hall, K. F. (2012). Multiple-choice exams: An obstacle for higher-level thinking in introductory science slasses. CBE Life Sciences Education, 11(3), 294-306. doi: 10.1187/cbe.11$11-0100$

Tiwari, A., Lai, P., So, M., \& Yuen, K. (2006). A comparison of the effects of problem-based learning and lecturing on the development of students' critical thinking. Medical Education, 40(6), 547-554. doi:10.1111/j.1365-2929.2006.02481.x 